\title{
ON GOVERNMENT-INDUSTRY NEXUS AND INDIGENOUS ARMED RESISTANCE
}

Soumyanetra Munshi

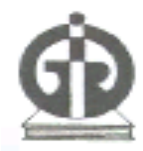

Indira Gandhi Institute of Development Research, Mumbai March 2015

http://www.igidr.ac.in/pdf/publication/WP-2015-04.pdf 


\title{
ON GOVERNMENT-INDUSTRY NEXUS AND INDIGENOUS ARMED RESISTANCE
}

\author{
Soumyanetra Munshi \\ Indira Gandhi Institute of Development Research (IGIDR) \\ General Arun Kumar Vaidya Marg \\ Goregaon (E), Mumbai- 400065, INDIA \\ Email(corresponding author): soumyanetra@igidr.ac.in
}

\begin{abstract}
This paper proposes a simple game-theoretic framework for analyzing the relationship between the government, industry and indigenous community, especially in the context of mounting violence surrounding displacement of indigenous communities by governments for the purposes of commercial use of their habitat. It specifically takes into account the possibility of alleged 'nexus' between the government and the industry and explores its implications on the levels of conflict and utilities of the players. We find that under plausible asymptotic conditions, the counter-resistance measures of the industry in the 'no-nexus' regime is higher than that of the government in 'nexus' regime. Moreover, both the government and the industry are likely to be better-off in the 'nexus' regime while the indigenous community is better-off in the 'no-nexus' regime.
\end{abstract}

Keywords: Government-industry nexus, indigenous community, armed rebellion

JEL Code: D72, D74, H11, P48 


\title{
ON GOVERNMENT-INDUSTRY NEXUS AND INDIGENOUS ARMED RESISTANCE
}

\author{
SOUMYANETRA MUNSHI
}

\begin{abstract}
This paper proposes a simple game-theoretic framework for analyzing the relationship between the government, industry and indigenous community, especially in the context of mounting violence surrounding displacement of indigenous communities by governments for the purposes of commercial use of their habitat. It specifically takes into account the possibility of alleged 'nexus' between the government and the industry and explores its implications on the levels of conflict and utilities of the players. We find that under plausible asymptotic conditions, the counter-resistance measures of the industry in the 'no-nexus' regime is higher than that of the government in 'nexus' regime. Moreover, both the government and the industry are likely to be better-off in the 'nexus' regime while the indigenous community is better-off in the 'no-nexus' regime.
\end{abstract}

\section{INTRODUCTION}

There is an MoU on every mountain, river and forest glade. We're talking about social and environmental engineering on an unimaginable scale.(Roy [20])

Modern world is replete with armed conflicts and about 90 per cent of them has been intrastate (Chenoy and Chenoy [9], Collier and Hoeffler [12]). Each of these insurgencies and conflicts have different features and histories but often patterns and trends can be identified among them. For example, there is empirical evidence that abundance of mineral resources is positively and significantly related to armed conflict (Soysa [23]). And often this arises from forced displacement of indigenous communities whose habitats get increasingly encroached upon by large corporates trying to gain access to the minerals (see Blaser et al. [3] for an account of such resistance in North and South America, and Somayaji and Talwar [24], Anderson and Huber [1], for the case in India, to name a few). The government also plays a key role, in both providing the nod to the private players in going ahead with operations in such resource-rich areas, as well as rehabilitation measures of the displaced communities (see Cernea [8], for example). Allegations of mutually convenient arrangements, monetary and otherwise, between the government and corporate houses at the cost of further deprivation and humiliation of the indigenous communities are also not uncommon, which leads to further conflagration, armed resistance and gory outcomes. This paper is an attempt to provide an analytical framework for exploring this tripartite relation between the government, profit-seeking identities like MNCs etc., generically called the industry, and the local indigenous community.

Key words and phrases. Armed conflict, Government-industry nexus, Indigenous armed resistance. 
Modern businesses are typically large corporate houses or multinational corporations which often operate in developing countries using resources from these countries ${ }^{1}$. In India, for instance, huge mineral deposits in the hills of Eastern and Central India have attracted tremendous corporate interest but has unfortunately seen some ghastly bloodshed as well (Chenoy and Chenoy [9], Roy [20]). The situation gets compounded with the local inhabitants (tribals or adivasis) getting help from and often identifying themselves with Maoists who in turn fortify their ranks with the help of these disgruntled tribals ${ }^{2}$. In fact the Maoist insurgency in India (aided and abetted by the tribals and hence forming an amorphous insurgent group) has turned much more bloody relative to 1960's when Maoism first gained ground and momentum in India. The annual number of victims in this conflict is now close to a thousand (Gayer and Jaffrelot [13]).

Moreover, it is often alleged that governments often join hands with these large corporates who are mostly MNCs to facilitate their operations in spite of such hostile local environments. During 1970's and early 1980's, national governments often opposed MNC entry (Calvano [6]). However, with economic globalization of the 1990's, we see increased cooperation between MNCs and national governments (Luo [16]). Luo succintly put it as follows, "MNCs and governments are interdependent on each other for critical resources in today's world economy. Sharing resources cooperatively creates more payoffs for both than controlling privately. This cooperation can create synergies because their resources are often complementary and their interests compatible." He elaborates how governments and MNCs especially strengthen their long-term relations once the MNC has begun operations ${ }^{3}$ since

\footnotetext{
${ }^{1}$ According to recent data, out of 100 largest "economies" in the world, only 47 of them are nation states, the other 53 are MNCs. Exxon Mobil Corporation, for example, has annual revenues that exceed the GDP of all but 20 of the world's 220 nations. (Carroll [7])

${ }^{2}$ In India, the rise of Maoism or Naxalism (after the place Naxalbari where the movement first begun) has come to be entangled with armed resistance of the displaced communities. The areas that are Naxaliteaffected are part of the 187 forest districts that cover $63 \%$ of dense forests (covered by the Fifth and Sixth Schedules of the Constitution) and which are home to major mineral deposits like coal, tin, bauxite and iron ore (Chenoy and Chenoy [9]). Exploitation of forest produce and mining of minerals are certainly at the heart of Maoist insurgency. In 2008 an expert group appointed by the Planning Commission submitted a report called Development Challenges in Extremist Affected Areas, which said "the Naxalite (Maoist) movement has to be recognised as a political movement with a strong base among the landless and poor peasantry and adivasis. Its emergence and growth need to be contextualized in the social conditions and experience of people who form a part of it. The huge gap between state policy and performance is a feature of these conditions. Though its professed long-term ideology is capturing state power by force, in its day-today manifestation, it is to be looked upon as basically a fight for social justice, equality, protection, security and local development."

${ }^{3}$ In India, there are allegations of widespread favors being bestowed on MNCs arising out of government$\mathrm{MNC}$ nexus. For example, the signing of contracts worth $\$ 1.6$ billion with power industries by the Chhattisgarh government coincided with the launch of Salwa Judum, which allegedly helped to forcefully evict tribals from their villages. Similarly, the Jharkhand government has signed contracts with the Tata, Birla, Essar and other groups for aluminum and iron-ore plants. According to the Planning Commission report in 2008 , whereas tribals constitute $8.08 \%$ of the country's population, they form $40 \%$ of the displaced. In Andhra Pradesh, for example, where contracts for bauxite-mining has been given to the Jindals and the Anrak Group, mining operations will displace about 100,000 tribals and employ only 400 of them.

Resistance by indigenous groups often lead to violence and death like in Ghana where "in November 2005, police officers in the Brim North District of Ghana's Eastern Region shot and killed a resident and
} 
"governments themselves can also be important customers, suppliers, or partners of large transactions conducted by MNCs". Moreover, he recognizes how this continued cooperation leads to a shift in the paradigm of regulation of the MNC by the government "from overt to covert and from direct to indirect".

With such a background in mind, we propose a framework to analyze various issues concerning the players. To begin with, we have analyzed two models - one where there is alleged 'nexus' between the government and the industry in the form of joint maximization of objectives in return of monetary favors being bestowed by the industry on the government, and the other where such a nexus is absent. In the 'nexus' model (Game 1), the industry makes a monetary contribution to the government and then the government chooses a level of allocation of a public resource between the industry and the indigenous group. This is a somewhat standard approach taken in the analysis of special interest politics (see Grossman and Helpman [15], for example) where interest groups contribute in order to influence policy outcomes. However in these settings, since the focus is on the interest group, not much attention is paid to behavior of the unorganized group, against whom such 'biased' allocations are likely to act. Our attempt here is to extend such an analysis to include the possibility of the hitherto unorganized group to rise in armed rebellion against such allocations under alleged nexus.

Hence, in the next stage of the game, the indigenous group resists to such allocation of the natural resource and rises in armed resistance against allocation decisions of the government. That is, the indigenous group makes investments in conflict which are countered by the government with its own investments in conflict. Hence in the next stage of the game, both the indigenous group and the government simultaneously choose the level of investment in armed conflict with each other. Outcomes are probabilistic and probabilities depend on investments made by the parties in conflict (in this case the government and the indigenous community).

injured three others during a protest against Newmont Mining Company's proposed method to compensate local farmers for economic losses." (Calvano [6]) Again, "the government of Ecuador declared a state of emergency in northeastern Napo province to quash violent protests by indigenous communities aimed at disrupting Occidental Petroleum's production in the rainforest." (Calvano [6])

We see such instances extensively in Latin America as well. According to Ward [25], "From the mid1960s the Brazilian government introduced a system of subsidies and fiscal incentives which particularly favoured large-scale Amazonian cattle ranching. ... Corporate enterprises,... secured extensive land grants, and displaced, often violently, considerable numbers of peasant settlers who had occupied small holdings without legal title. ... Settler penetration into Amazonia was helped by government road construction, and the logging trails established to extract timber." No doubt the government was a helpful ally in such corporate initiatives and expansion. He also notes, specifically with respect to mining, "Mining development also occurred on a large-scale capitalist basis, most notably through the undertaking formed to exploit the Carajas iron ore deposits, discovered in 1967. ... By the mid-1980s... Amazon tree cover was being lost through felling and burning at an accelerating rate, and suggesting that much of the region would be entirely deforested within a few years ... and contribute to 'greenhouse effect'. ... There was concern too over the threatened loss of potentially valuable biological species." 
As opposed to this model, in the 'no-nexus' model (Game 2), we assume that there is no nexus between the government and the industry so that here the government decides on a level of allocation of the public good without being subject to any kind of influence from any of the parties. However whenever there is allocation of the public good, there is resistance by the indigenous group since it means taking away of resources over which they have been enjoying undivided ownership rights. So our interest will mainly be in comparing the levels of resistance in a situation of alleged nexus versus that in a no-nexus situation.

Moreover, in the no-nexus situation, we assume that counter-resistance measures are mainly undertaken by the industry (as opposed to them being undertaken primarily by the government under nexus). Hence the industry now heavily invests in measures of rehabilitation, monetary compensation etc. (often included in the umbrella term 'Corporate Social Responsibility', CSR) to counter conflict investments by the indigenous group. The industry in principle, can undertake CSR measures even when it is in nexus with the government, but to keep things simple, we assume that in case of nexus government undertakes the bulk of rehabilitation/counter-resistance/displacement-related measures while in its absence, the industry shoulders the onus. Hence in the next stage of the no-nexus game, the indigenous group and the industry invest in conflict and CSR (primarily counter-resistance) measures respectively and simultaneously. Again, outcomes are probabilistic and probabilities depend on investments made by the parties in conflict (in this case the industry and the indigenous group).

We find that under some plausible asymptotic conditions, retaliation measures/conflict investments of the industry (in the no-nexus model) are always higher than that of the government (as in the nexus model). In other words, counter-resistance measures faced by the indigenous group is higher in the nexus relative to the no-nexus regime. However, the rebellion by the indigenous community may or may not higher than the other across the two regimes.

Moreover, we find that both the government and the industry are likely to be better off in the nexus model than the no-nexus model, while the indigenous community will be betteroff under the no-nexus regime than the nexus regime. The conclusions somewhat help to rationalize the widespread existence of such alleged government-industry nexus regimes in many countries and at the same time point out to the plight of the indigenous groups in such circumstances.

Related Thoughts and Literature. The topic of the paper borders on several strands of literature and disciplines. It undoubtedly belongs to the economics literature that models conflicts and civil wars. Much research, for example, talks about the economics behind civil 
strife which essentially says that rebellion happens when its benefits outweigh its costs (see Azam [2], Collier and Hoeffler [11], Grossman [14], and Reuveny and Maxwell [21], to name a few). Collier and Hoeffler [12] try to analyze civil wars according to its root cause. The idea is that some wars arise primarily due to greed in the sense of some agents wanting to capture valuable resources for purposes of trade and export thereby causing grievance in the process leading to rebellion of the affected people. On the other hand, some civil strife are grievance-driven like revolts of ethnic or religious minorities against some decision/behavior of the majority group for example. Our model definitely has the flavor of the first category though our model is quite different overall. Interestingly, our model can also be related to the second category since the people who are "wronged" in some sense, from whom the valuable resource is being taken away, also happen to be the indigenous community, who are ethnically different and often a minority who tare typically backward and underdeveloped as well. As Collier and Hoeffler empirically show, most civil strife is best explained by a model that combines the two sources of strife - greed grievance.

In a similar vein, our model can be related to the "resource-curse" literature which says that the greater is natural resource abundance, the higher is the probability of conflict (see Wick and Bulte, [26], for example). Of course, the model starts with the presence of a resource which is hitherto in the control of an indigenous community, and its redistribution causes conflict in the model. However, that is not the only cause. The novelty of the model lies in that it shows how a possible nexus between the industry and the government can further exacerbate this conflict.

The model, at some intrinsic level, rests on the philosophical plane that discusses rights of indigenous people. See Nozick [17], for example for a classic reference of such views that encompass the struggles of the indigenous people, inevitably enmeshed in pressures from the government and the market-place ${ }^{4}$. See also Oldham and Frank [18], Quane [19].

The no-nexus model also importantly rests on the possibility of the industry stepping in to combat conflict investments by the indigenous community. These are often referred to as efforts at CSR (Corporate Social Responsibility). The World Business Council for Sustainable Development (WBCSD) has defined CSR as "the continuing commitment by business to behave ethically and contribute to economic development while improving the quality of life of the workforce and their families as well as of the local community and society at large" (Blowfield and Frynas [5]). In India, companies operate under the provisions of the Companies Act 2013 which explicitly recognizes a basic moral and social responsibility

\footnotetext{
${ }^{4}$ Two noteworthy implications of Nozick's philosophy are that the state may not use its coercive apparatus for the purpose of getting some citizens to aid others, or in order to prohibit activities of the people for their own good or protection.
} 
of companies towards the society in which they operate. Under this Act, mid and large companies have to spend 2 percent of their three-year annual average net profit on CSR activities. The Indian government is expecting considerable outlay of such expenses.

Hence in theory, CSR is an umbrella term to cover basic rules of operation of MNCs in distant locations. For example, a few norms are as follows: "MNCs should do no intentional, direct harm; produce more good than bad for the host country; contribute to the host country's development; respect human rights; pay their fair share of taxes; respect the local culture; and cooperate with the host government in developing ethical background institutions (e.g., health and safety standards)." (Carroll [7]) However like many things on paper which remains far from practice, many global business ethics issues plague businesses today. Ethical issues surrounding MNCs fall into at least eight major categories: "bribery and sensitive payments, employment issues, marketing practices, impact on the economy and development of host countries, effects on the natural environment, cultural impacts of operations, relations with host governments, and relations with home countries." (Carroll $[7])$

Typically, therefore the potential contribution of CSR is to increase profitability. Hence especially with spread of business in developing economies since the I980s, there have been frequent complaints that companies exploit the social and environmental conditions of such countries echoing Milton Friedman's famous statement that there is "only one social responsibility of business: to use its resources and engage in activities designed to increase its profit". Hence it is now widely recognized that often some of the people in developing countries (the local indigenous communities, for example) are ignored or marginalized by CSR, "because they were either not acknowledged or were too difficult to manage". In fact, the question that Blowfield and Frynas sound out remains unanswered in the management literature, "Can corporations, built on a western economic model, recognize values rooted in other cultures?"

Unfortunately therefore, with total disregard of guiding principles ${ }^{5}$ "there are many instances in which multinationals have used their muscle to push through sensitive policies and gain preferential benefits in ways that have been deeply resented in the countries concerned. Multinational corporations, as much as governments, are therefore often seen to reflect alien cultures and interests which become a threat to the identity and independence of people in

\footnotetext{
${ }^{5}$ In India for example, the government has alleged that 'Greenpeace' and other NGOs were using antinuclear, anti-genetic modified food and anti-coal agitations to negatively impact GDP growth in the country. In a second report, it recommended cancellation of the permission given to Greenpeace for collecting funds abroad. "We have in our campaigns made enough stakeholders extremely uncomfortable. The nexus between industry and government is a well-known plot....some people are really upset." The NGO said it was specifically targeted for having emerged as one of the primary voices against coal mining and nuclear projects (which are MNC operated) in India.
} 
the countries where they operate." Such a sense is definitely prevalent in many places where they operate like in India. The attitude of the host government seems to be "that the benefits to their country's interests, and sometimes their own pockets, outweigh a consideration of what their citizens think." (Child [10])

The rest of the paper is organized as follows: section 2 presents the two models; section 3 derives the main implications of the models regarding levels of conflict and welfare of the parties; section 4 concludes.

\section{The Model}

There are three players/parties - the government, the industry and the indigenous community. Let the government be denoted by player $G$, the corporation be player 1 and the indigenous community be player 2. Player $G$ has to allocate a natural resource of amount $g$ between players 1 and 2 . Assume that the natural resource is initially within the custody of player 2 (the indigenous community) and they are ready to put up armed and violent resistance against player $G$ (or the industry as in the second model) in the event of any part of it being given to player 1 . Let $g_{1}$ be the amount of $g$ that the government announces to allocate to player 1. Hence player 2's share is $g-g_{1}$ amount of the public good.

We will analyze two basic models in this context - a model where there is an alleged nexus between the government and the industry (group 1) and the other where there is none.

2.1. Government-Industry-Nexus Model (Nexus Model). We model nexus in the following way: Group 1 makes monetary transfers to the government that are valuable to it. Let us call it 'campaign contributions' and denote it by $c$. Moreover the government and group 1 jointly decide on the level of $g_{1}$ and $c$.

Now given any level of $g_{1}$, group 2 can engage in conflict and let $f_{2}$ be the amount it invests in conflict. Government can retaliate using force and let that be denoted by $f_{G}$. Hence the timeline for this model (call it Game 1) will be as follows:

Stage 1: Government and group 1 jointly decide on the levels of $g_{1}$ and $c$.

Stage 2: Group 2 chooses $f_{2}$ and government chooses $f_{G}$ simultaneously.

Given $f_{2}$ and $f_{G}$, let the probability of success be given by the usual ratio-form contest success function (see Skaperdas [22], for example). That is, the probability that group 2 wins is given by $f_{2} /\left(f_{2}+f_{G}\right)$ while the government wins with the remaining probability. Assume moreover, that if 2 wins, it can retain the entire amount of $g$ (that is group 1 gets nothing) while if it loses, it gets the share that government allocates to it in stage 1 of the game $\left(g-g_{1}\right)$. 
Assume also that both group 2 and the government evaluate costs of conflict using an increasing and convex cost function of the form $f_{i}^{2} / 2$ for conflict investment of an amount $f_{i}, i=G, 2$.

Moreover let group 1 evaluate the resource using an increasing and concave function $V_{1}($. (this is assumed to be a Cobb-Douglas function later) while group 2 evaluates it using $V_{2}$ (increasing and concave). Let the government's utility be a weighted sum of utilities of the two groups as well as campaign contributions. Let us now specifically write down the utility functions of the parties.

The expected utility of player 1 is given by

$$
\begin{aligned}
U_{1} & =\frac{f_{2}}{f_{2}+f_{G}}\left(V_{1}(0)-c\right)+\frac{f_{G}}{f_{2}+f_{G}}\left(V_{1}\left(g_{1}\right)-c\right) \\
& =\frac{f_{2}}{f_{2}+f_{G}} V_{1}(0)+\frac{f_{G}}{f_{2}+f_{G}} V_{1}\left(g_{1}\right)-c .
\end{aligned}
$$

That is, if group 2 wins, then group 1 gets nothing of the public good while if the government wins, it gets $g_{1}$ amount, and it incurs the payment $c$ irrespective of the outcome of the government-group 2 conflict. Similarly, the expected utility of player 2 is given by (here the cost of conflict is being borne by group 2 irrespective of the outcome)

$$
U_{2}=\frac{f_{2}}{f_{2}+f_{G}} V_{2}(g)+\frac{f_{G}}{f_{2}+f_{G}} V_{2}\left(g-g_{1}\right)-\frac{f_{2}^{2}}{2} .
$$

The expected utility of the government is given by

$$
\begin{aligned}
U_{G}= & \frac{f_{2}}{f_{2}+f_{G}}\left(\alpha_{G}\left(V_{1}(0)+V_{2}(g)\right)+\left(1-\alpha_{G}\right) c-\frac{f_{G}^{2}}{2}\right) \\
& +\frac{f_{G}}{f_{2}+f_{G}}\left(\alpha_{G}\left(V_{1}\left(g_{1}\right)+V_{2}\left(g-g_{1}\right)+\left(1-\alpha_{G}\right) c-\frac{f_{G}^{2}}{2}\right)\right. \\
= & \frac{f_{2}}{f_{2}+f_{G}}\left(\alpha_{G}\left(V_{1}(0)+V_{2}(g)\right)\right. \\
& +\frac{f_{G}}{f_{2}+f_{G}}\left(\alpha_{G}\left(V_{1}\left(g_{1}\right)+V_{2}\left(g-g_{1}\right)\right)+\left(1-\alpha_{G}\right) c-\frac{f_{G}^{2}}{2} .\right.
\end{aligned}
$$

Here $\alpha_{G}$ is the weight government gives to the sum of the utilities of the two groups while $\left(1-\alpha_{G}\right)$ is the weight it assigns to the contribution it receives from the industry. Hence in the event that group 2 wins, it puts weight $\alpha_{G}$ on $V_{1}(0)+V_{2}(g)$ which is the sum of the resulting utilities of the two groups when group 2 has won, while it puts weight $\alpha_{G}$ on $V_{1}\left(g_{1}\right)+V_{2}\left(g-g_{1}\right)$ which is the sum of the resulting utilities of the two groups when the government has won. It incurs the cost of conflict in all scenarios.

We use backward induction to solve the model. Hence given levels of $g_{1}$ and $c$, we first solve for the optimal levels of conflict, that is, government chooses $f_{G}$ to maximize (3) and group 2 chooses $f_{2}$ to maximize (2), simultaneously. The following proposition summarizes the findings: 
Proposition 1. Let $V_{1}\left(g_{1}\right)-V_{1}(0)=v_{1}, V_{2}(g)-V_{2}\left(g-g_{1}\right)=v_{2}$. Moreover, let $v_{1}>v_{2}$. Then the optimal levels of conflict in stage 2 of Game 1 are given by

$$
\begin{aligned}
& f_{2}^{*}=\frac{v_{2}^{3 / 4}\left(v_{1}-v_{2}\right)^{1 / 4} \alpha_{G}^{1 / 4}}{\sqrt{\alpha_{G}\left(v_{1}-v_{2}\right)}+\sqrt{v_{2}}} \\
& f_{G}^{*}=\frac{v_{2}^{1 / 4}\left(v_{1}-v_{2}\right)^{3 / 4} \alpha_{G}^{3 / 4}}{\sqrt{\alpha_{G}\left(v_{1}-v_{2}\right)}+\sqrt{v_{2}}} .
\end{aligned}
$$

Here $v_{1}$ can be interpreted as 'what is at stake' for group 1 while $v_{2}$ can be interpreted as 'what is at stake' for group 2 and we have assumed that $v_{1}>v_{2}$, that is, 'what is at stake' is higher for group 1 than group 2.

Now let us turn to stage 1. In this stage, joint maximization of the government and the industry entails a level of campaign contribution which leaves the government indifferent between accepting and not accepting the contribution. In other words, the industry will not offer any more than they have to in order to influence the policy $\left(g_{1}\right)$. Hence to determine the solution, it will help to solve for the 'reservation utility' level of the government, that is the utility which the government enjoyed pre-campaign-contribution. For simplicity, assume that there is no conflict as well.

\subsubsection{Government's reservation utility level sans campaign contributions and conflict. Let} the government allocate a public good between two groups and suppose there is no other tension in the economy. Suppose that the government is equally concerned about the welfare of both the groups. Government's problem is as follows:

$$
\max _{g_{1}} V_{1}\left(g_{1}\right)+V_{2}\left(g-g_{1}\right) .
$$

First order condition for maximization implies

$$
V_{1}^{\prime}\left(g_{1}\right)=V_{2}^{\prime}\left(g-g_{1}\right)
$$

That is, the good is allocated between the two groups till the marginal benefit from the good is equalized across the groups ${ }^{6}$. Let the resulting $g_{1}$ be denoted as $\hat{g}_{1}$. We can plug back the optimal allocation, $\hat{g}_{1}$ in (6) and find the reservation utility level of the government, call it $\hat{U}_{G}$ where

$$
\hat{U}_{G}=V_{1}\left(\hat{g}_{1}\right)+V_{2}\left(g-\hat{g}_{1}\right) .
$$

\footnotetext{
${ }^{6}$ Notice that in the special case of $V_{1}=V_{2},(7)$ can be solved to yield

$$
\hat{g}_{1}=g / 2 .
$$

Hence the optimal allocation of the public good entails an equal distribution of the good among the two groups. And the utility of the government at the optimal solution in this special case, can be calculated to be $2 V(g / 2)$. In the more general case, when the two groups evaluate the resource using different functions, the distribution need not be equal.
} 
Hence joint maximization of the government and the industry implies solving the following problem:

$$
\begin{aligned}
& \max _{g_{1}, c} U_{1} \\
& \text { subject to } U_{G} \geq \hat{U}_{G} .
\end{aligned}
$$

Since $c$ is purely a deduction from the utility of group 1 , it will try to make $c$ as small as possible without violating the individual rationality (IR) constraint of the government. Therefore, it must be the case that at the optimal solution IR will bind, that is $U_{G}=\hat{U}_{G}$. This then yields that

$c=\frac{1}{1-\alpha_{G}} \hat{U}_{G}+\frac{1}{1-\alpha_{G}} \frac{f_{G}^{* 2}}{2}-\frac{\alpha_{G}}{1-\alpha_{G}} \frac{f_{2}^{*}}{f_{2}^{*}+f_{G}^{*}}\left(V_{1}(0)+V_{2}(g)\right)-\frac{\alpha_{G}}{1-\alpha_{G}} \frac{f_{G}^{*}}{f_{2}^{*}+f_{G}^{*}}\left(V_{1}\left(g_{1}\right)+V_{2}\left(g-g_{1}\right)\right)$.

Hence (10) reduces to an unconstrained maximization as follows:

$$
\begin{aligned}
\max _{g_{1}}\left\{\frac{f_{2}^{*}}{f_{2}^{*}+f_{G}^{*}} V_{1}(0)+\frac{f_{G}^{*}}{f_{2}^{*}+f_{G}^{*}} V_{1}\left(g_{1}\right)-\frac{1}{1-\alpha_{G}} \bar{U}_{G}-\frac{1}{1-\alpha_{G}} \frac{f_{G}^{* 2}}{2}\right. \\
\left.\quad+\frac{\alpha_{G}}{1-\alpha_{G}} \frac{f_{2}^{*}}{f_{2}^{*}+f_{G}^{*}}\left(V_{1}(0)+V_{2}(g)\right)+\frac{\alpha_{G}}{1-\alpha_{G}} \frac{f_{G}^{*}}{f_{2}^{*}+f_{G}^{*}}\left(V_{1}\left(g_{1}\right)+V_{2}\left(g-g_{1}\right)\right)\right\} .
\end{aligned}
$$

Differentiating w.r.t. $g_{1}$ yields the FOC for the allocation of the resource among the two groups as follows:

$$
\frac{f_{2}^{*} f_{G}^{*}\left(v_{1}-\alpha_{G} v_{2}\right)\left(v_{2}^{\prime} v_{1}-v_{1}^{\prime} v_{2}\right)}{2 v_{2}\left(v_{1}-v_{2}\right)\left(f_{2}^{*}+f_{G}^{*}\right)^{2}}=\frac{f_{G}^{*}}{f_{2}^{*}+f_{G}^{*}}\left(v_{1}^{\prime}-\alpha_{G} v_{2}^{\prime}\right)-f_{G}^{*} \frac{\partial f_{G}}{\partial g_{1}} .
$$

To get closed-form predictions, we consider specific functional forms of the Cobb-Douglas type for the functions $V_{1}$ and $V_{2}$. Let

$$
\begin{aligned}
& V_{1}(x)=A_{1} x^{\beta}, \\
& V_{2}(x)=A_{2} x^{\beta} .
\end{aligned}
$$

For simplicity, let us normalize $A_{2}$ to 1 and assume $A_{1}>1$. Now let $A_{1}^{\frac{1}{\beta-1}}=A$ and $\alpha_{G}^{\frac{1}{\beta-1}}=\alpha$. Now since $A_{1}>1, \beta<1$, we have $A<1$. Also, $\alpha_{G}<1$ and $\beta<1$, hence $\alpha>1$. Given optimal conflict levels in stage 2 of Game 1 as in Proposition 1, the optimal allocation of $g$ in stage 1 is given by the following proposition:

Proposition 2. Let $\beta>1 / 3, \alpha \rightarrow \infty$, and $A \rightarrow 0$ such that $\alpha A$ is bounded and bounded away from 0 . Then $g_{1}^{*} \rightarrow 0$.

Idea of the proof: Taking taylor series expansion of terms with exponents and then taking the leading order terms under asymptotic assumptions as given in the statement of the proposition, we get the the above result.

Hence according to the proposition, the indigenous community can potentially retain the entire public resource when it rises in armed rebellion. 
In contrast, let us now turn to a model where there is no nexus between the government and industry.

2.2. No-Government-Industry-Nexus Model (No-Nexus Model). We model no nexus in the following way: There is no payment which the industry makes to the government. So the government announces an allocation that is not 'biased' to begin with. But since there is some reallocation of $g$ away from group 2 there is conflict and assume now that the industry itself bears costs of resistance from group 2. In fact these costs can be interpreted as costs of 'corporate social responsibility' (CSR) wherein the industry tries to provide rehabilitation benefits etc. to the displaced communities.

Hence let given any level of $g_{1}$, group 2 invest $\tilde{f}_{2}$ in conflict while let industry retaliate using $\mathrm{CSR} /$ counter-resistance measures $^{7}$ and let that be denoted by $\tilde{f}_{1}$. Hence the timeline for this model (call it Game 2) will be as follows:

Stage 1: Government chooses $g_{1}$.

Stage 2: Group 1 chooses $\tilde{f}_{1}$ and Group 2 chooses $\tilde{f}_{2}$ simultaneously.

We will naturally be interested to see how $f_{2}^{*}$ and $\tilde{f}_{2}$ compares - that is whether conflict is likely to be higher or lower when there is alleged nexus between the government and the industry. It will also be interesting to see how retaliation efforts (of the government and the industry) compare across the nexus versus the no-nexus regimes.

The expected utility of player 1 is given by

$$
U_{1}=\frac{f_{1}}{f_{1}+f_{2}} V_{1}\left(g_{1}\right)+\frac{f_{2}}{f_{1}+f_{2}} V_{1}(0)-\frac{f_{1}^{2}}{2} .
$$

That is, if it wins, it gets the allocation provided by the government but if it doesn't, then it gets nothing. Similarly, the expected utility of group 2 is being given by

$$
U_{2}=\frac{f_{1}}{f_{1}+f_{2}} V_{2}\left(g-g_{1}\right)+\frac{f_{2}}{f_{1}+f_{2}} V_{1}(g)-\frac{f_{2}^{2}}{2} .
$$

The expected utility of the government is given by

$$
U_{G}=\frac{f_{1}}{f_{1}+f_{2}}\left(V_{1}\left(g_{1}\right)+V_{2}\left(g-g_{1}\right)\right)+\frac{f_{2}}{f_{1}+f_{2}}\left(V_{1}(0)+V_{2}(g)\right) .
$$

\footnotetext{
${ }^{7}$ From various sources on the Internet for example, we find that NALCO (National Aluminum Company Limited) engages in the following CSR activities: The Company has four mobile health units, which organized 1357 camps in 2010-11 and treated 65340 patients with free medicines. During 2011-12, till December 2011, 769 camps have been organized and 36043 patients have been treated with free medicines. Moreover, NALCO Foundation has come forward to set up an Industrial Training Institute (ITI) at Marichamal village in the tribal-dominated Koraput, under the aegis of district administration. To run the mobile health units more professionally, the organization has taken up a project with Wockhardt Foundation. Similarly, for the formal education of tribal children, NALCO Foundation is sponsoring 250 children to Kalinga Institute of Social Sciences (KISS), Bhubaneswar. To mitigate the menace of malaria and many water-borne diseases, projects have been taken up to distribute mosquito nets and water filters in 18 villages of Damanjodi sector.
} 
Notice that now the government does not incur any cost of counter-resistance measures. We use backward induction to solve the model. Hence given level of $g_{1}$ from stage 1 of Game 2 , we first solve for the optimal levels of conflict investments made by the two groups in stage 2 , that is, group 1 chooses $f_{1}$ to maximize (16) and group 2 chooses $f_{2}$ to maximize (17), simultaneously. The following proposition summarizes the findings:

Proposition 3. Let $V_{1}\left(g_{1}\right)-V_{1}(0)=v_{1}, V_{2}(g)-V_{2}\left(g-g_{1}\right)=v_{2}$. Moreover, let $v_{1}>v_{2}$. Then the optimal levels of investments in conflict in stage 2 of Game 2 are given by

$$
\begin{aligned}
& \tilde{f}_{1}=\frac{v_{1}^{3 / 4} v_{2}^{1 / 4}}{\sqrt{v_{1}}+\sqrt{v_{2}}} \\
& \tilde{f}_{2}=\frac{v_{1}^{1 / 4} v_{2}^{3 / 4}}{\sqrt{v_{1}}+\sqrt{v_{2}}} .
\end{aligned}
$$

In stage 1 of Game 2, the government takes the conflict investment levels as given in proposition 3 and maximizes (18). Let the resulting optimal $g_{1}$ be denoted by $\tilde{g}_{1}$. Given optimal conflict levels in stage 2 of Game 2 as in Proposition 3, the optimal allocation of $g$ in stage $1, \tilde{g}_{1}$, is as given in the following proposition:

Proposition 4. Let $A \rightarrow 0$. Then $\tilde{g}_{1} \rightarrow 0$.

Idea of the proof: Taking taylor series expansion of terms with exponents and then taking the leading order terms under asymptotic assumptions as given in the statement of the proposition, we get the the above result.

Hence the allocation of the good moves in favor of group 2 (to pre-conflict levels) when there is no nexus between the government and the industry.

\section{ANALYSIS}

In this section we will see how conflict levels and welfare of the players vary across the two regimes.

3.1. Comparison of conflict investment levels. Let us now compare the levels of investment in conflict technology by the indigenous resistance group, group 2. That is, let us compare $f_{2}^{*}$ (the level of investment with government-industry nexus) and $\tilde{f}_{2}$ (the level sans any nexus but with rehabilitation/CSR like measures undertaken by the industry). It is also interesting to compare the levels of counter-resistance measures of the government to that of the industry in the two models. That is, how does $f_{G}^{*}$ compare with $\tilde{f}_{1}$ ?

General comparisons are quite indeterminate and hence to get closed-form predictions, we consider specific functional forms of the Cobb-Douglas type for the functions $V_{1}$ and $V_{2}$ as mentioned earlier. Further, let $g=1$ (that is let the size of the entire resource to be allocated between the two groups be 1). Then the following proposition summarizes the findings: 
Proposition 5. Let $\alpha \rightarrow \infty$ and $A \rightarrow 0$. Then $\tilde{f}_{1}>f_{G}^{*}$. Also $\tilde{f}_{2}>f_{2}^{*}$, if $\beta<\beta^{*}$, whereas $\tilde{f}_{2}<f_{2}^{*}$, if $\beta>\beta^{*}$.

Idea of the proof: Taking taylor series expansion of terms with exponents and then taking the leading order terms under asymptotic assumptions as given in the statement of the proposition, we get the the above result.

Hence we see that retaliation measures of the industry (in the no-nexus model) are always higher than that of the government (as in the nexus model).

However, the rebellion by the indigenous community may or may not higher than the other across the two regimes - for low $\beta$ conflict is higher against the industry (in the nexus regime) than the government (in the no-nexus regime) whereas it is the opposite for high $\beta$.

3.2. Comparison of utility levels. Let us now compare the utility levels of the government, industry and group 2 across the two models of nexus and no-nexus.

Now substituting the values of $f_{G}^{*}$ and $f_{2}^{*}$ (from equations (5) and (4) respectively) in $U_{G}$ (3), we get the utility level of the government in the nexus model in terms of $v_{1}^{*}$ and $v_{2}^{*}$. Call it $U_{G}^{*}$. (Note that campaign contribution received by the government, $c$, can be written in terms of $v_{1}^{*}$ and $v_{2}^{*}$ too.) Similarly, by substituting the values of $\tilde{f}_{1}$ and $\tilde{f}_{2}$ (from equations (19) and (20) respectively) in $U_{G}(18)$, we get the utility level of the government in the nexus model in terms of $\tilde{v}_{1}$ and $\tilde{v}_{2}$. Call it $\tilde{U}_{G}$. We can do similar exercises for groups 1 and 2. The following proposition summarizes the findings:

Proposition 6. Let $\alpha \rightarrow \infty$ and $A \rightarrow 0$. Then $U_{G}^{*}>\tilde{U}_{G}, U_{1}^{*}>\tilde{U}_{1}$ and $\tilde{U}_{2}>U_{2}^{*}$.

Idea of the proof: Taking taylor series expansion of terms with exponents and then taking the leading order terms under asymptotic assumptions as given in the statement of the proposition, we get the the above result.

Hence, we see that the government is likely to be better off in the nexus model than the nonexus model, a plausible justification for why governments enter nexus regimes voluntarily. The industry also, as expected, is better-off in the nexus regime than the no-nexus regime. However the indigenous community is better-off under the no-nexus regime than the nexus regime.

\section{Conclusion}

We have proposed a very simple set-up to see the ramifications of alleged nexus between the government and the industry in the context of allocation of a public resource and under the possibility of armed resistance by the indigenous group who are initially the primary 
users of the resource. We see distortion of public good allocation possibly being countered by armed rebellion of the indigenous community. We see higher conflict investments by the industry in the no-nexus regime than that by the government in the nexus regime whereas the level of resistance by the indigenous group can vary across regimes. The government and the industry are likely to be better off under the nexus regime while the indigenous community is better off in the no-nexus regime.

There is further scope for enriching the model. For example, can we endogenize the choice of regimes? That is, can we endogenously answer the question as to who fights group 2 (it is the government in the nexus regime and the industry in the no-nexus one)? In other words, it is possible, and likely, given the utilities of the government and industry in the two regimes, that group 1 actually prefers to delegate the decision to fight to the government (in exchange for contribution), so that we have the nexus regime rather than the no-nexus regime emerging as the equilibrium outcome of a bigger game that endogenizes the decision of regimes. This will then rationalize the widespread existence of such regimes in many countries in today's world.

On a different note, within the existing framework, we can think of 'campaign contribution' as government revenue, at least part of which is spent on public goods or transfers elsewhere, in a context where the government faces a revenue constraint ${ }^{8}$. So, if we do admit the possibility of higher $c$ improving social welfare, at least for the non-tribal population (not explicitly modeled here), we move into a different set of public policy trade-offs. In fact, one could interpret the state's valuation of $c$ in terms of some kind of relative state capture by non-tribals so that a more democratic state would then go for higher expropriation of tribals. We could do some explicit welfare comparisons between tribals and non-tribals as well: a utilitarian social welfare function could easily mandate high expropriation of tribals despite higher conflict, whereas a Rawlsian one might mandate otherwise.

\section{REFERENCES}

[1] Anderson, Robert S., and Huber, Walter (1988) The Hour of the Fox: Tropical Forests, the World Bank, and Indigenous People in Central India. Vistaar Publications, New Delhi.

[2] Azam, Jean-Paul. (1995) How to Pay for the Peace? A Theoretical Framework with References to African Countries. Public Choice, Vol. 83, No. 1/2, pp. 173-184.

[3] Blaser, Mario, Feit, Harvey A., and McRae, Glenn. (2004) In the way of Development: Indigenous Peoples, Life Projects and Globalization, Zed Books, London and New York.

[4] Boddewyn, Jean J. and Brewer, Thomas L. (1994) International-Business Political Behavior: New Theoretical Directions. The Academy of Management Review, Vol. 19, No. 1, pp. 119-143.

\footnotetext{
${ }^{8}$ For example, fiscal transfers in India tend to be disjoint from the financial contribution by a region. For instance, the revenue generated from mining and natural resources is generally used for large social and infrastructure needs, but not necessarily in that region where the revenue is raised. There are different arguments in support of this practice the foremost being that the central government has a larger development responsibility as natural resources are unevenly distributed across states. (Political Economy of Land Acquisition and Resource Development in India by Shashi Ratnaker Singh. Paper presented in the'Political Economy of Development' conference at IGIDR, Mumbai, during November 2014.
} 
[5] Blowfield, Michael and Frynas, Jedrzej George. (2005) Setting New Agendas: Critical Perspectives on Corporate Social Responsibility in the Developing World, International Affairs, Vol. 81, No. 3, pp. 499-513.

[6] Calvano, Lisa. (2008) Multinational Corporations and Local Communities: A Critical Analysis of Conflict, Journal of Business Ethics, 82(4), pp. 793-805.

[7] Carroll, Archie B. (2004) Managing Ethically with Global Stakeholders: A Present and Future Challenge. The Academy of Management Executive, Vol. 18, No. 2, pp.114-120.

[8] Cernea, Michael (ed.) (1999) The Economics of Involuntary Resettlement: Questions and Challenges, The world Bank, Washington.

[9] Chenoy, Anuradha M., Chenoy, Kamal A. Mitra,. (2010) Maoist and Other Armed Conflicts. Penguin Books, India.

[10] Child, John. (2002) The International Crisis of Confidence in Corporations. The Academy of Management Executive, Vol. 16, No. 3, pp.145-147.

[11] Collier, Paul and Hoeffler, Anke (1998) On Economic Causes of Civil War. Oxford Economic Papers, Vol. 50, No. 4, pp. 563-573.

[12] Collier, Paul and Hoeffler, Anke (2004) Greed and Grievance in Civil Wars. Oxford Economic Papers, Vol. 56, No. 4, pp. 563-595.

[13] Gayer, Laurent and Jaffrelot, Christophe (2009) Armed Militias of South Asia: Fundamentalists, Maoists and Separatists, Foundation Books.

[14] Grossman, H.I. (1995) 'Insurrections', in K. Hartley and T. Sandler (eds), Handbook of Defence Economics, Vol. I, Elsevier Science B.V., Amsterdam.

[15] Grossman, Gene and Helpman, Elhanan (2001) Special Interest Politics, The MIT Press.

[16] Luo, Yadong. (2001) Toward a Cooperative View of MNC-Host government Relations: Building Blocks and Performance Implications, Journal of International Business Studies 32(3), pp. 401-419.

[17] Nozick, Robert. (1974) Anarchy, State, and Utopia. Blackwell Publishers, Oxford, UK.

[18] Oldham, Paul and Anne, Frank. (2008) 'We the Peoples...' the United Nations Declaration on the Rights of Indigenous Peoples. Anthropology Today, Vol. 24, No. 2, pp. 5-9.

[19] Quane, Helen. (2005) The Rights of Indigenous Peoples and the Development Process. Human Rights Quarterly, Vol. 27, No. 2, pp. 652-682.

[20] Roy, Arundhati. (2011) Broken Republic: Three Essays. Hamish Hamilton (an imprint of Penguin Books), India.

[21] Reuveny, Rafael, and Maxwell, John W. (2001) Conflict and Renewable Resources. The Journal of Conflict Resolution, Vol. 45, No. 6, pp. 719-742.

[22] Skaperdas, Stergios (1996) Contest Success Functions. Economic Theory, Vol. 7. 283 - 290

[23] Soysa, Indra de (2000) The Resource Curse: Are Civil Wars Driven by Rapacity or Paucity? in Berdal, Mats and Malone, David M., (eds) Greed and Grievance: Economic Agendas in Civil Wars, Lynne Rienner Publishers, Inc. Colorado.

[24] Somayaji, Sakarama, and Talwar, Smrithi (eds.) (2011) Development-induced Displacement, Rehabilitation and Resettlement in India: Current Issues and Challenges. Routledge Publication, London and New York.

[25] Ward, John. (1997) Latin America: Development and Conflict since 1945. Routledge, London and New York.

[26] Wick, Katharina, and Bulte, Erwin H. (2006) Contesting Resources: Rent Seeking, Conflict and the Natural Resource Curse. Public Choice, Vol. 128, No. 3/4, pp. 457-476.

Indira Gandhi Institute of Development Research (IGIDR)

E-mail address: soumyanetra@igidr.ac.in 